\title{
OBSERVATIONS UTILIZING KOREA OCEAN RESEARCH STATIONS AND THEIR APPLICATIONS FOR PROCESS STUDIES
}

Kyung-Ja Ha, Sunghyun Nam, Jin-Yong Jeong, Il-Ju Moon, Meehye Lee, Junghee Yun, Chan Joo Jang, Yong Sun Kim, Do-Seong Byun, Ki-Young Heo, and Jae-Seol Shim

Ocean-atmosphere observations utilizing the Korea ocean research stations are available to the scientific community to advance our understanding of air-sea interactions, atmospheric chemistry, oceanographic processes, and more.

$\mathrm{T}$ he Yellow and East China Seas are contained in a shallow, marginal seas surrounded by mainland China to the west and Korea and Japan to the east. More than $75 \%$ of the area of this region is shallower than $100 \mathrm{~m}$; thus, it is among the most productive continental shelf regions in the world. Heo et al. (2012) showed that warming in the East China and Yellow Seas has been more rapid than global warming. Therefore, even a small environmental change can have an ecological impact on the region and an economic influence on the people living along the coast.

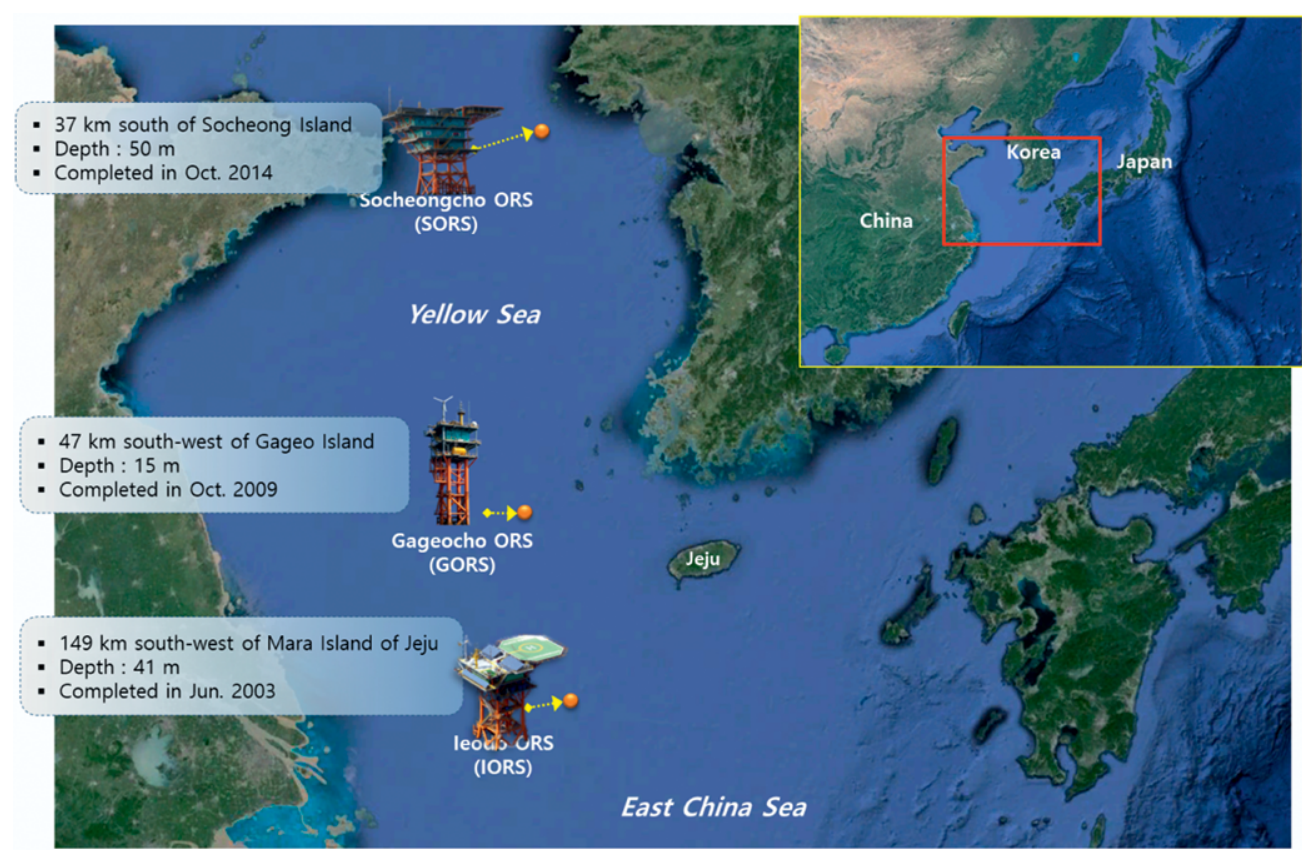

FIG. I. Location of the Korea ocean research stations in the Yellow and East China Seas. 
Overview of ocean platforms. Ocean observing platforms were established to explore these environmental variabilities at multiple scales. There are three main Korea ocean research stations (KORS): the Ieodo ORS (I-ORS; established in June 2003), the Gageocho ORS (G-ORS; established in October 2009), and the Socheongcho ORS (S-ORS; established in October 2014) (Fig. 1). The KORS are steel-framed tower-type platforms designed to monitor long-term oceanic variability, enabling interdisciplinary scientific investigation. Located at the boundary between the Yellow and the East China Seas, which is a location through which typhoons frequently pass, the initial station, the I-ORS, is the most suitable for monitoring various oceanic, meteorological, and coastal phenomena, including typhoons, freshwater discharged from the Changjiang River, the local branches of the Kuroshio, the East Asian monsoon system, and air-sea interactions (Lie et al. 2003; Lie and Cho 2016; Y. S. Kim et al. 2018; Park et al. 2011; Yun et al. 2018). The more recently constructed G-ORS and S-ORS, north of the I-ORS, allow us to monitor the meridional connectivity of atmospheric and oceanic signals. Approximately 20 research programs are ongoing as of November 2018. Scientists can attach their own sensors to those of the KORS and conduct investigations of ocean processes at or near the stations. The KORS have wet laboratories useful for biogeochemical measurements and facilities for staying for several days without supplies.

AfFiliations: HA AND YUN-Center for Climate Physics, Institute for Basic Sciences, and Department of Atmospheric Sciences, Pusan National University, Busan, South Korea; NAMSchool of Earth and Environmental Sciences, and Research Institute of Oceanography, Seoul National University, Seoul, South Korea; JeONG, Jang, Kim, HeO, aNd ShIm-Korea Institute of Ocean Science and Technology, Busan, South Korea; MooN-Typhoon Research Center, Jeju National University, Jeju, South Korea; LeEDepartment of Earth and Environmental Science, Korea University, Seoul, South Korea; BYUN-Ocean Research Division, Korea Hydrographic and Oceanographic Agency, Busan, South Korea CORRESPONDING AUTHOR: Kyung-Ja Ha, kjha@pusan.ac.kr; SungHyun Nam, namsh@snu.ac.kr

The abstract for this article can be found in this issue, following the table of contents.

DOI:10.1175/BAMS-D-18-0305.I

In final form 26 May 2019

(C)2019 American Meteorological Society

For information regarding reuse of this content and general copyright information, consult the AMS Copyright Policy.

This article is licensed under a Creative Commons Attribution 4.0 license.
The main purposes of these KORS are for improving comprehensive oceanic and weather observations, providing core scientific information and data for regional and global environmental change studies, investigating typhoon dynamics (Choi et al. 2013; Moon and Kwon 2012; Moon et al. 2010), providing basic information for fisheries and sea fog prediction (Heo and $\mathrm{Ha} 2010$; Heo et al. 2014) as well as regional oceanographic studies (Nam et al. 2018; Song et al. 2018), functioning as a ground station for satellite oceanic remote sensing (Kang et al. 2017), and investigating the movement and distribution of atmospheric constituents such as Asian dust and aerosols (Han et al. 2015; Lee et al. 2017).

\section{OPERATION AND MEASUREMENTS.}

Operation and maintenance. The KORS, first established by the Korea Institute of Science and Technology (KIOST), has been operated and sustained under the Korea Hydrographic Oceanographic Agency (KHOA). The KIOST is mainly responsible for conducting atmospheric and oceanic process studies using the data observed at the KORS. The system of the KORS was designed, manufactured, and operated as an unmanned ocean observing platform with a lifespan of 50 years or more. The main power sources are solar and wind energies, and in case of power shortage, diesel generators supply the power to the KORS. The data collected at the KORS are being transmitted to land in real time via satellite, and the operators control the facilities remotely via the satellite as well as on site.

The KORS is located more than $100 \mathrm{~km}$ away from land, and it is rather difficult to maintain when compared to a coastal ocean observing system. The KORS is supposed to be serviced typically four times a year mainly during the warm season of March-November except August when severe weather events prevail such as typhoon and heavy rainfall by the Asian summer monsoon. Researchers can stay at the KORS for almost a week of each month during this period to conduct their own measurements and research activities. The KHOA has been conducting a program of "I-ORS field trip" since 2014. The Haeyang Nuri, a dedicated ship to service the I-ORS, transports up to 20 operators and researchers to and from the station, $150 \mathrm{~km}$ away from a port of Jeju Island. No specific vessel is allocated to G-ORS and S-ORS yet, and commercial vessels are used to access there. The KHOA selects the proposals submitted by researchers for the in situ observational research programs in and around the KORS in a yearly basis, and the ship schedules each year is determined considering the selected proposals. 
Instrumentation and data. The three stations, I-ORS, G-ORS, and S-ORS, possess instruments designed to obtain data for use in various disciplines. The stations are used to measure conductivity-temperature-depth (CTD), speed and direction of horizontal currents, and ocean surface wave and bulk meteorology parameters, etc., as schematically shown in Fig. 2. The atmospheric variables include speed and direction of horizontal wind, air temperature, pressure, humidity, precipitation, solar radiation, ultraviolet (UV) radiation, and amount of daylight. A typical sampling interval for these variables is $1 \mathrm{~min}$. The oceanographic variables such as surface wave parameters (wave height, wave period, and wave direction), temperature and salinity (at 5-, 20-, and 40-m depth over the entire study period and 3, 5, $10,15,20,30,40$, and $50 \mathrm{~m}$ during the summer at the I-ORS station), speed and direction of horizontal current, sea level, underwater ambient noise, and biogeochemical variables including nutrients and chlorophyll a, are measured. A

\section{KORS}

Three main ocean research stations (KORS) of leodo ORS (I-ORS, beginning June 2003), Gageocho ORS (G-ORS, beginning October 2009), and Socheongcho ORS (S-ORS, beginning October 2014) have been installed. These are currently in operation and possess instruments used in a variety of disciplines, including CTDs and devices designed to study currents/waves, bulk meteorology, etc. The primary goal of obtaining these data are for improving comprehensive ocean and atmosphere observations, providing core scientific information for studying global environmental changes, investigating typhoon dynamics, providing basic information to fisheries and for ocean fog prediction, conducting regional ocean studies, functioning as a ground station of satellite sea remote sensing work, and investigating the movement and distribution of atmospheric constituents, such as Asian dust and aerosols.

Variables considered in this study (including the heights and depths at which they were measured) are wind, air temperature, pressure, humidity, precipitation, solar radiation, UV radiation, and amount of daylight, whose sampling interval is I min. Oceanographic variables were wave parameters (wave height, wave period, and wave direction), temperature and salinity (5-, 20-, and 40-m depth over the entire period, and 3-, 5-, 10-, 15-, 20-, 30, 40-, and 50-m depth in the summer), current, sea level, and underwater ambient noise. The biogeochemical variables were nutrients; plankton, whose sampling interval varied from I to $10 \mathrm{~min}$, except the biogeochemical variables; and atmospheric particles, including $\mathrm{PM}_{2.5}$, black carbon, $\mathrm{CO}, \mathrm{CO}_{2}, \mathrm{O}_{3}, \mathrm{H}_{2} \mathrm{O}$, and $\mathrm{CH}_{4}$, whose sampling interval was $\mathrm{I} h$. The atmospheric and core oceanographic measurements are currently provided at I-h intervals in real time via the Korea Sea Observation and Forecasting System (KOOFS). Additional high-frequency time series, such as I-min interval data, are available.

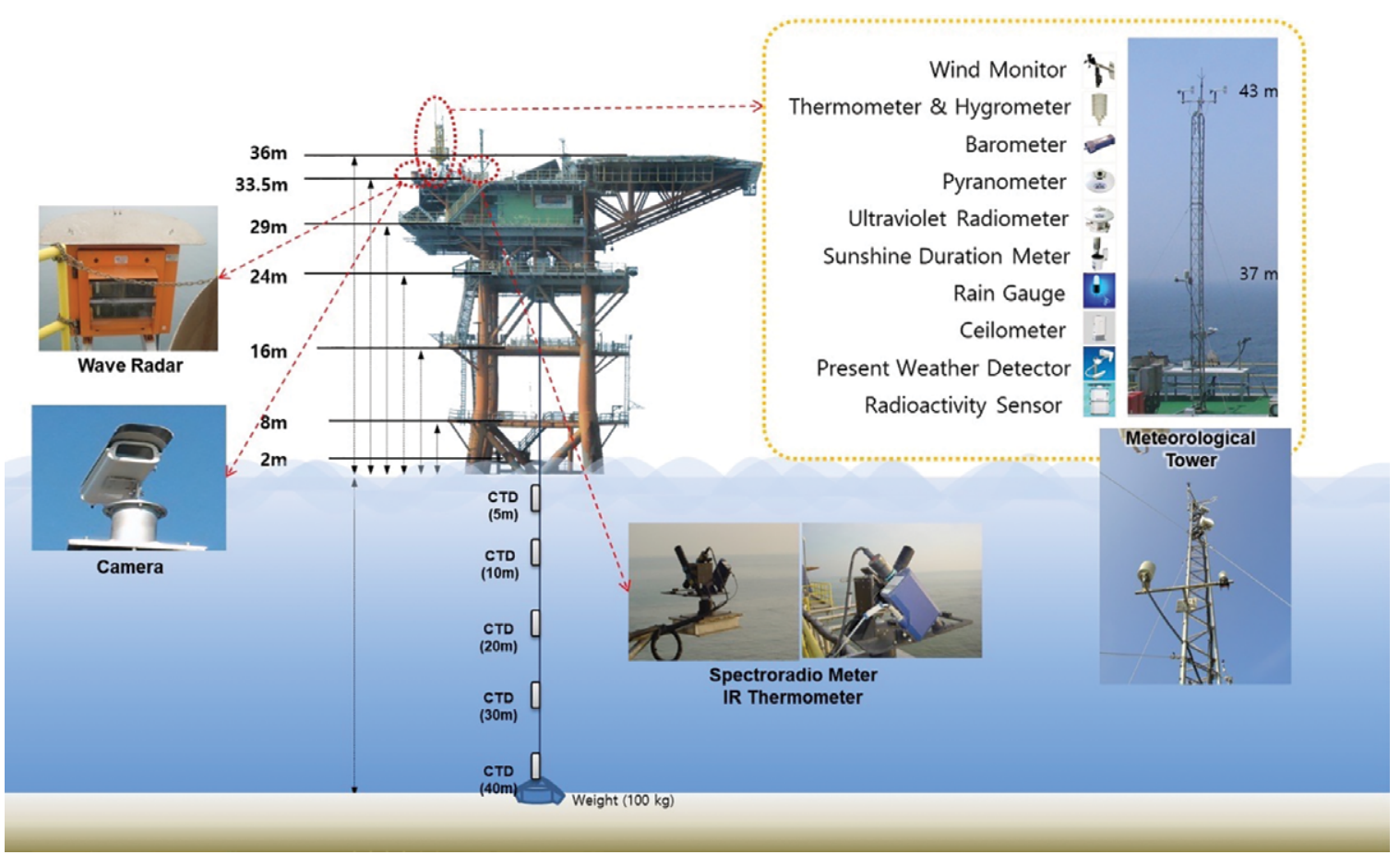

FIG. 2. Structure of the ocean research station and main sensors. 
variables about which information is obtained include atmospheric particles ( $\mathrm{PM}_{2.5}$ and black carbon), $\mathrm{CO}$, $\mathrm{CO}_{2}, \mathrm{O}_{3}, \mathrm{H}_{2} \mathrm{O}$, and $\mathrm{CH}_{4}$. Because their measurement frequency is different from instrument to instrument, the 10-min averages are archived except for $\mathrm{PM}_{2.5}$ mass that needs to be collected for $30 \mathrm{~min}$. Atmospheric and core oceanographic measurements are provided every hour in real time via the Korea Oceanographic Observation and Forecasting System (KOOFS) operated by the KHOA. Higher-frequency time series, such as data collected at 1-min intervals, are archived to be checked when needed. In situ vertical profiling measurements are also provided in a delayed mode. Figure 3 shows observational data from a time series obtained during 2003 to 2017 at the I-ORS. In addition to fixed ocean observing platforms, such as the I-ORS, moorings, bottom mounts, mobile platforms, and mobile ocean observing platforms like underwater robots with enhanced payload have been developed and utilized to improve oceanographic sampling. A variety of fleets and multiplatform observing sensors will be utilized in and around the KORS in the future.
This will result in synergies to enhance the resolution/ monitoring of the variability occurring at multiple scales in space and time (Nam et al. 2014). The I-ORS is used to test new and existing ocean observing platforms and develop an effective sampling strategy.

A prime goal of the data quality control process is to obtain a reasonable scientific observation by flagging as few bad measurements as possible. In addition, the process is designed to process various time series (or sensor outputs) with a standard procedure. The KORS sit on the shallow water column under severe atmospheric and oceanic fluctuations. Moreover, they have experienced diverse practical problems such as biofouling for subsurface sensors, intermittent power shortage, and signal interference between sensors. These environmental and technical limitations need a strict quality control procedure for time series obtained at the KORS. This method that we devised has two levels of quality control for real time and delay distributions: automatic and human-inthe-loop quality control. At the first level, outliners are automatically flagged based on quality checks

\section{Air temperature}

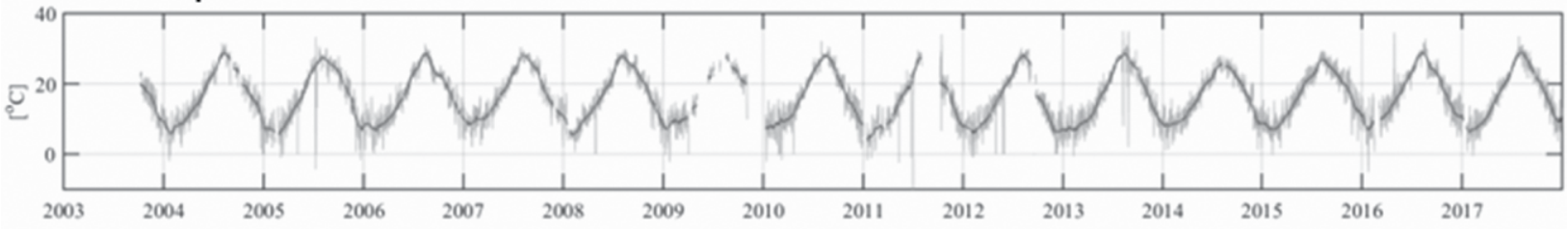

Wind speed

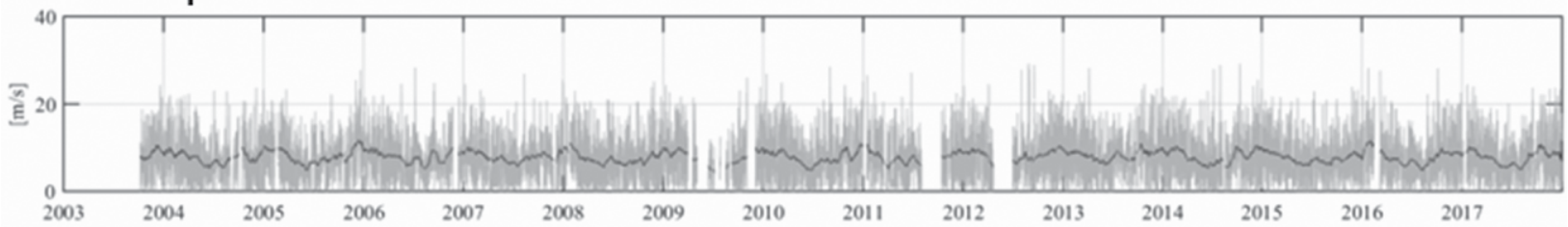

Sea temperature

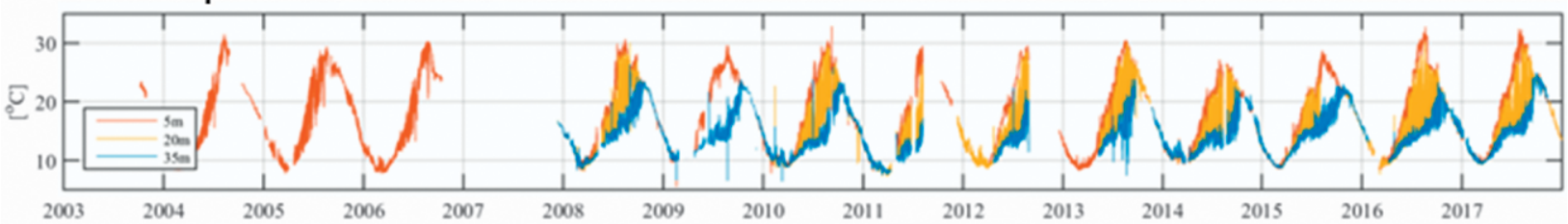

Wave height

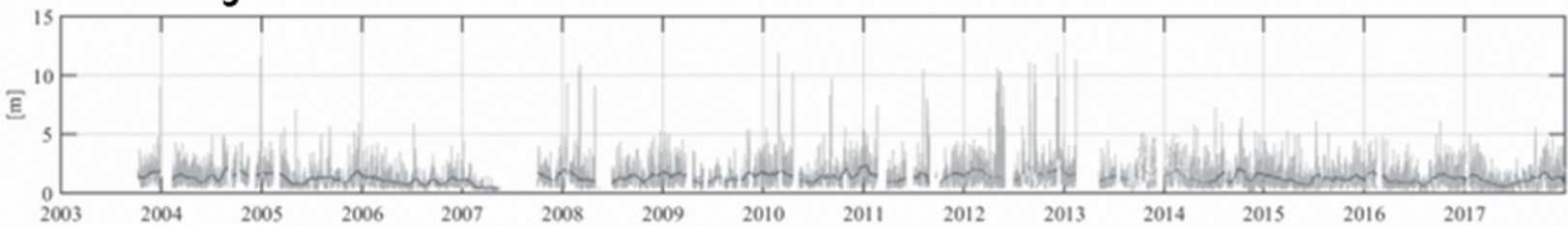

Fig. 3. Examples of observed time series of (from top to bottom) air temperature, wind speed, water temperature (at 5, 20, and $35 \mathrm{~m}$ shown in orange, yellow, and blue colors), and wave height measured at the I-ORS for 15 years from 2003 to 2017. 
including local data range, spike, stuck value, and standard deviation based on moving windows. At the second stage, measurements that were recorded during cleansing, relocation, replacement of a sensor, and any maintenance are flagged based on a field note. The final time series are then reexamined subjectively by illustrating them along with concurrent, relevant observations. If a coherent event is also recorded in the other measurements, we restore previously flagged data into possibly good one during this stage. This tends to happen in case of an extreme weather event such as typhoon passing near the KORS. In this case, extremely cold anomalies at the water surface layer and warm anomalies at the bottom layer go with abrupt drops of sea level pressure, as well as wind bursts.
Obtained conductivity (and thus salinity) is subject to severe biofouling, especially during warm seasons. Several antifouling experiments have been conducted for this purpose. In situ CTD profiles and water samples have been also collected on the KORS and used for calibrating temperature/salinity and biogeochemical sensors at a regular interval for sensor maintenance.

Because of severe weather conditions, heavy maritime transportation, and fishing activity, the sensors are frequently damaged. The KHOA and KIOST have been attempting to minimize this damage using optimized measurement techniques (Yi et al. 2013; W. Kim et al. 2018). The continuous and reliable time series constructed using data collected at or near the KORS have been used to check the accuracy of measurements,

\begin{tabular}{|c|c|c|c|}
\hline & Sensors (model, manufacturer) & Observation variables & $\begin{array}{l}\text { Period } \\
\text { (to present) }\end{array}$ \\
\hline \multirow{12}{*}{$\begin{array}{l}\text { Meteorological } \\
\text { sensors }\end{array}$} & Anemometer (05106, RM YOUNG) & Wind speed, wind direction, gust & $2003 \sim$ \\
\hline & Ultrasonic anemometer (VENTUS, Lufft) & Wind speed, wind direction & $2014 \sim$ \\
\hline & Thermo-hygrometer (HMPI55, Vaisala) & Air temperature, humidity & $2003 \sim$ \\
\hline & Barometer (PTB2IOB, Vaisala) & Air pressure & $2003 \sim$ \\
\hline & Visibility meter (PWD-2I, Vaisala) & Visibility & $2003 \sim$ \\
\hline & Pyranometer (MS-802, EKO) & Insolation & $2003 \sim$ \\
\hline & Pyranometer (CMP2I, Kipp and Zonen) & Insolation & $2014 \sim$ \\
\hline & Ultraviolet radiometer (CUV5, Kipp and Zonen) & UV insolation & $2014 \sim$ \\
\hline & $\begin{array}{l}\text { Sunshine duration meter (MS-093, EKO; CSD\#, } \\
\text { Kipp and Zonen) }\end{array}$ & Sunshine duration & $2003 \sim$ \\
\hline & Rain gauge (ERGH, ELP; RGI3, Vaisala) & Rainfall & $2003 \sim$ \\
\hline & 3D sonic anemometer (CSAT3, Campbell) & 3D wind components & $2004 \sim$ \\
\hline & Gas analyzer (EC-I50, Campbell) & $\mathrm{CO}_{2}, \mathrm{H}_{2} \mathrm{O}$ & 2004 \\
\hline \multirow{4}{*}{$\begin{array}{l}\text { Environmental } \\
\text { sensors }\end{array}$} & $\begin{array}{l}\text { Continuous Ambient Particulate Monitor } \\
\text { (FH62Cl4, Thermo Scientific) }\end{array}$ & $\mathrm{PM}_{2.5}$ & $2013 \sim$ \\
\hline & $\begin{array}{l}\text { Continuous Ambient Particulate Monitor } \\
\text { (FH62Cl4, Thermo Scientific) }\end{array}$ & $P M_{10}$ & 2018 \\
\hline & $\mathrm{O}_{3}$ monitoring (49I, Thermo Scientific) & $\mathrm{O}_{3}$ & $2005 \sim$ \\
\hline & $\begin{array}{l}\text { Black carbon monitoring (50I2 MAAP, } \\
\text { Thermo Scientific, Green Laboratory) }\end{array}$ & Black carbon & $2014 \sim$ \\
\hline \multirow{6}{*}{$\begin{array}{l}\text { Oceanic } \\
\text { sensors }\end{array}$} & CT (CT3919, Aanderaa) & Wind speed, wind direction, gust & $2003 \sim$ \\
\hline & CTD (RBR Concerto, RBR, Ltd.) & $\begin{array}{l}\text { Temperature, conductivity, salinity, } \\
\text { depth }\end{array}$ & 2003 \\
\hline & CTD (SBE 37, SBE 19plus, Sea-Bird Scientific) & $\begin{array}{l}\text { Temperature, conductivity, salinity, } \\
\text { depth, dissolved oxygen, chlorophyll a }\end{array}$ & 2014 \\
\hline & ADCP (WHSW300, RD Instruments) & Current profiling & $2014 \sim$ \\
\hline & Range finder (SM-I40, MIROS) & $\begin{array}{l}\text { Sea level height, wave height, } \\
\text { wave period }\end{array}$ & 2003 \\
\hline & Wave radar (SM-050, MIROS) & $\begin{array}{l}\text { Wave height, wave period, wave direc- } \\
\text { tion, current speed, current direction }\end{array}$ & 2003 \\
\hline
\end{tabular}


examine scientists' hypotheses, and investigate various types of oceanic and atmospheric processes. Studies involving environmental changes (examining sea level rise, global warming, etc.), air-sea interactions (measuring heat, $\mathrm{CO}_{2}, \mathrm{CH}_{4}$, etc.), typhoons, the surface mixed layer and internal waves (e.g., Nam et al. 2018), primary production and ocean acidification, and underwater noise and marine aerosols are ongoing (Choi and Noh 2006; Han et al. 2015; Heo et al. 2008; 2010; Kim and Choi 2006; Lee et al. 2006; Moon et al. 2016).

Each station is equipped with more than 30 types of sensors (Table 1). Observational data are transmitted in real time via satellite. Surface current monitoring using a high-frequency (HF) radar system has been tested at the I-ORS and will be permanently installed. The stations have been used to integrate temporal and spatial observations (including the development of autonomous vehicles). Wave imaging systems were installed in 2017.

METEOROLOGICAL OBSERVATIONS. The meteorological observations over the open ocean are invaluable for measuring surface fluxes, air-sea interaction, and allowing for fundamental measurements using key instruments. The I-ORS over the East China Sea is a favored place for sea fog because of its location of strong variability in sea surface temperature (SST), air temperature, and the difference (Heo et al. 2010). Heo et al. (2010) had shown that the I-ORS data captured cases of advection and steam fogs, which appear to be due to a change in air temperature following an abrupt change in wind direction, wind speed, and relative humidity. There are sea fog databases for three KORS since 2003.

To investigate the characteristics of wind fields over the open ocean, we compared the wind speed among the coastal stations and the I-ORS. Figure 4 is a histogram of the wind speed at both the I-ORS and the Moseulpo coastal stations during January 2005 to December 2017. The wind speed at the Moseulpo station is between 2 and $4 \mathrm{~m} \mathrm{~s}^{-1}$ and less than $8 \mathrm{~m} \mathrm{~s}^{-1}$, while the wind at I-ORS is much stronger than that at Moseulpo. The wind speed at the I-ORS has a broad range, reaching up to $20 \mathrm{~m} \mathrm{~s}^{-1}$. In 2018, the maximum wind speed of $43 \mathrm{~m} \mathrm{~s}^{-1}$ was recorded during the passage of Typhoon Soulik (Byun et al. 2018).

The I-ORS is located in the area likely to be affected by strong winds, which is primarily due to its location in the open ocean. The wind measurements from the I-ORS provide data for studying the relationship between surface fluxes and wind speed over the open ocean, free of surface topography. In addition, the relationship between the nature of surface fluxes and strong winds can be studied using these data. This is because the wind over the open ocean is free from orographic influence. The I-ORS wind measurements provide data for understanding synoptic conditions such as cold surges and monsoonal flow.

Flux observations. Fluxes are observed with openpath eddy covariance system containing a 3D sonic anemometer/thermometer and an open-path $\mathrm{CO}_{2} /$ $\mathrm{H}_{2} \mathrm{O}$ gas analyzer. These instruments are mounted on the 16-m-high boom at the northwestern and southeastern directions. All signals of three-dimensional wind components, air temperature, air pressure, and $\mathrm{CO}_{2}$ and $\mathrm{H}_{2} \mathrm{O}$ concentration are sampled at $10 \mathrm{~Hz}$ and the turbulent fluxes (latent heat flux, sensible heat flux, friction velocity, etc.) are calculated using a constant 30 -min averaging time by the datalogger. The fast-response data should be corrected through the quality control to reduce abnormal information.

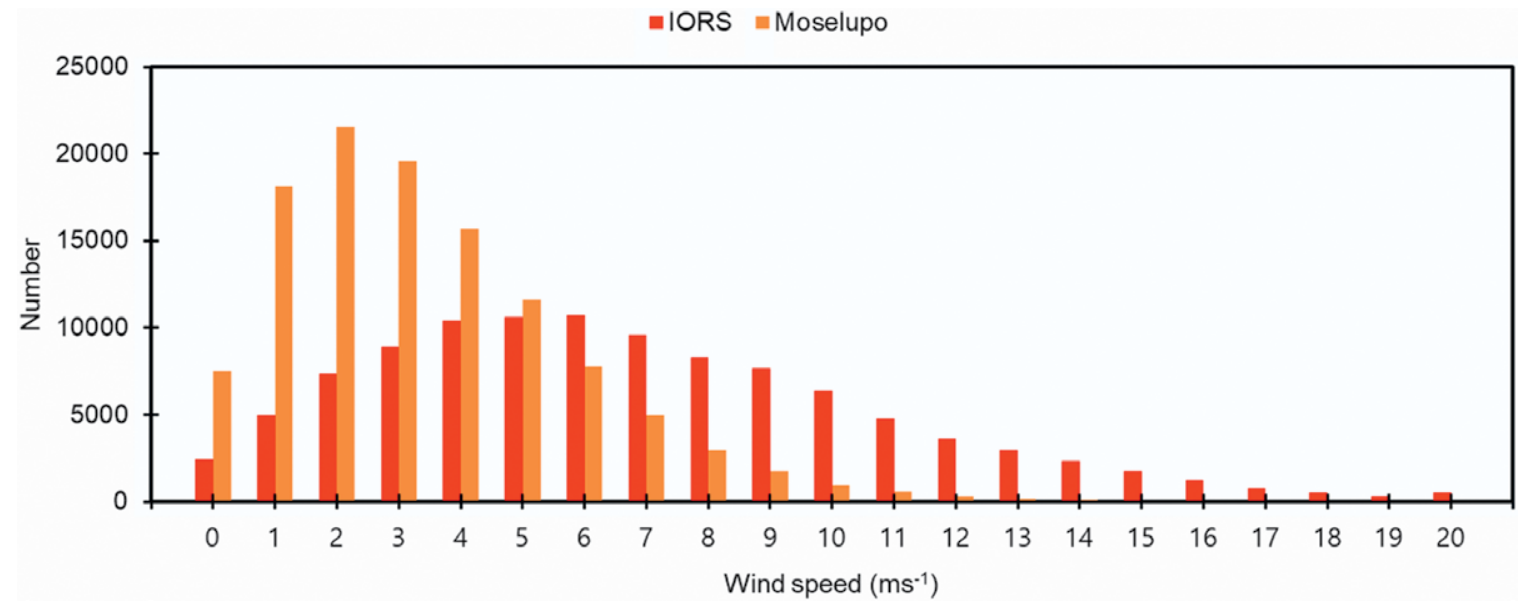

FIG. 4. Histogram of the hourly wind speed at the I-ORS and Moseulpo coastal stations during January 2005 to December 2017. 
A postprocessing algorithm including quality control and tilt correction designed by Oh et al. $(2010,2011)$ has contributed to improve the quality of I-ORS data.
The seasonal variation of heat fluxes is closely connected to that of temperature and humidity. In general, the relationship between friction velocity and (a) Spring

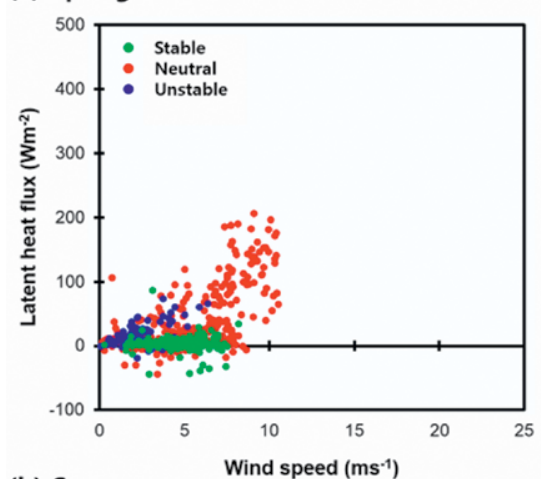

(b) Summer

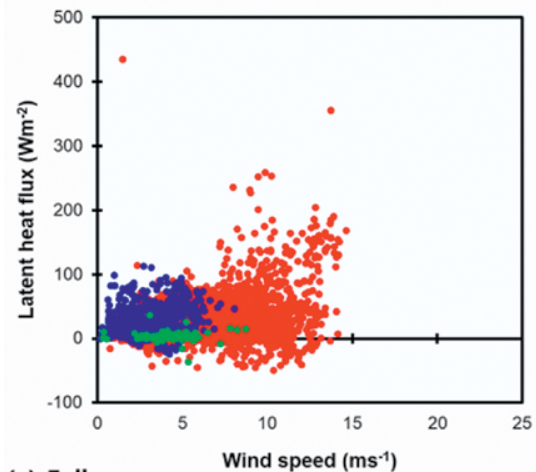

(c) Fall

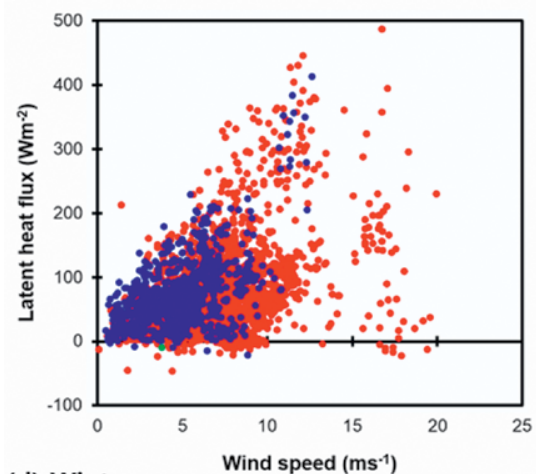

(d) Winter

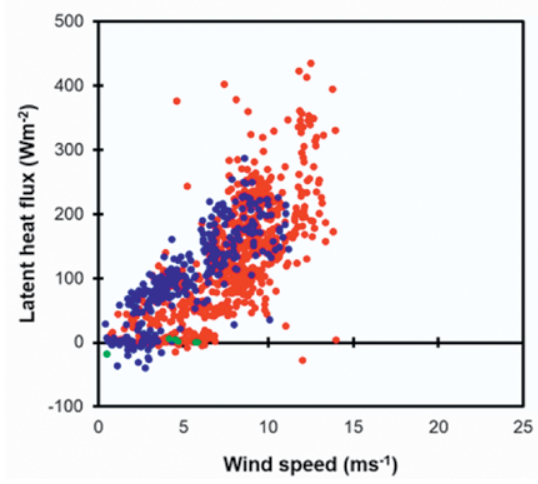

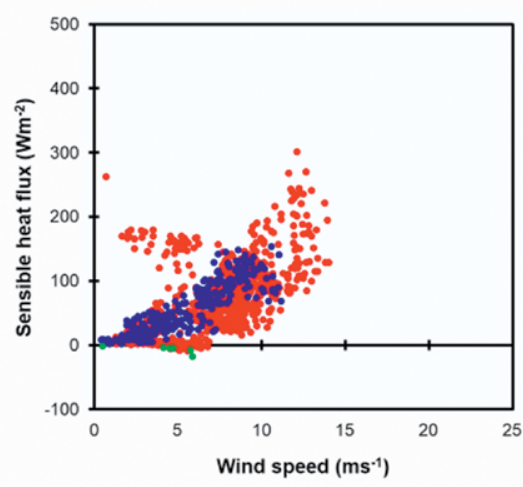
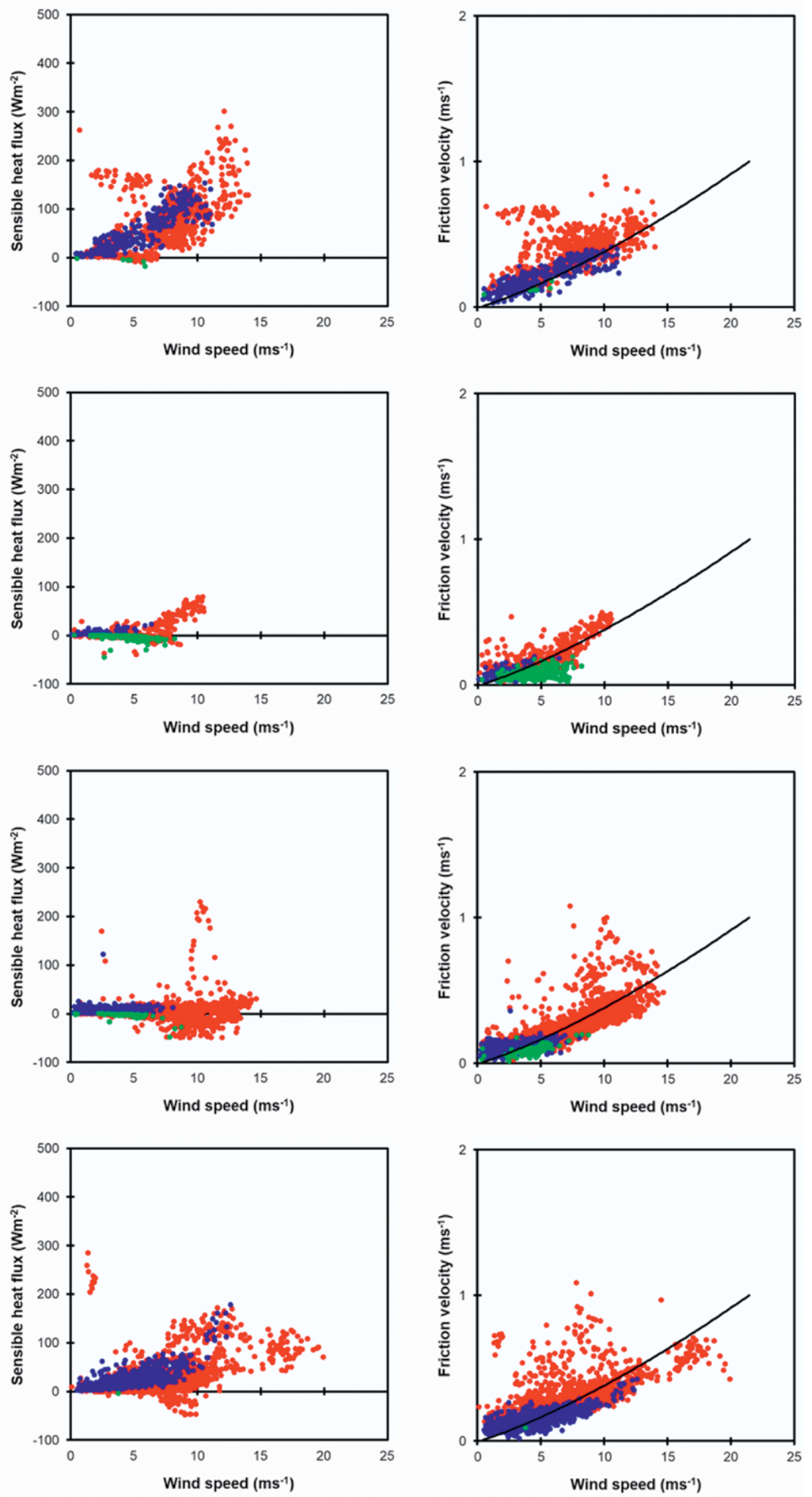

FIG. 5. (left) Latent heat flux, (middle) sensible heat flux, and (right) friction velocity as a function of wind speed at the I-ORS during the period when the data are available at the I-ORS during (a) spring (March-May), (b) summer (June-August), (c) fall (September-November), and (d) winter (December-February). 
wind speed depends on Monin-Obukhov's similarity theory (Ha and Mahrt 2001). To understand seasonal characteristics of the surface fluxes over the Yellow Sea, seasonal air-sea fluxes were plotted as a function of wind speed for sample data collected during the intensive periods when the data are available at the I-ORS (Fig. 5). The fluxes are divided by three parts with stability for stable, neutral, and unstable state, which has been hinted by the classification of nocturnal boundary layer over land (Ha et al. 2007). It can be noted that these periods are sufficient in sampling for demonstrating seasonal features. From seasonal characteristics of the surface fluxes, it is shown that the latent heat flux increases rapidly with the wind speed and is more scattered under the strong wind condition, especially during fall and winter. It has been demonstrated that latent heat flux can be influenced not only by the wind speed but also by sea surface roughness depended on wave height or wave age. The sensible heat flux has similar characteristic with the latent heat flux, but the value of sensible heat flux is generally lower than that of latent heat flux except for spring. The friction velocity follows roughly the similarity theory even though it is somehow overestimated while strong wind is observed under the neutral condition.

Typhoon and ocean wave applications. The I-ORS is in the open ocean, and typhoons frequently pass through the open ocean. Statistical analysis shows that an average of one typhoon every year passed within $150 \mathrm{~km}$ of the I-ORS during 1950 to 2016, and $54 \%$ of these made landfall on the Korean Peninsula (KP) (Moon et al. 2010). Figure 6a shows the tracks of typhoons that have passed near the I-ORS during 2003 to 2016, during which Typhoon Maemi was the strongest (the observed maximum wind speed was $35 \mathrm{~m} \mathrm{~s}^{-1}$; Fig. 6b) and the closest typhoon to the I-ORS during this period was Typhoon Ewiniar. Maemi, which passed over warm oceanic currents, maintained a strong intensity until landfall over the KP, while Ewiniar, which passed over the Yellow Sea Bottom Cold Water (YSBCW), underwent a dramatic intensity reduction. From the time series of water temperature observed at depths of $8,16,24,32,40$, and $48 \mathrm{~m}$ during the passage of Typhoon Ewiniar (Fig. 6c), it was found that upper-ocean temperatures
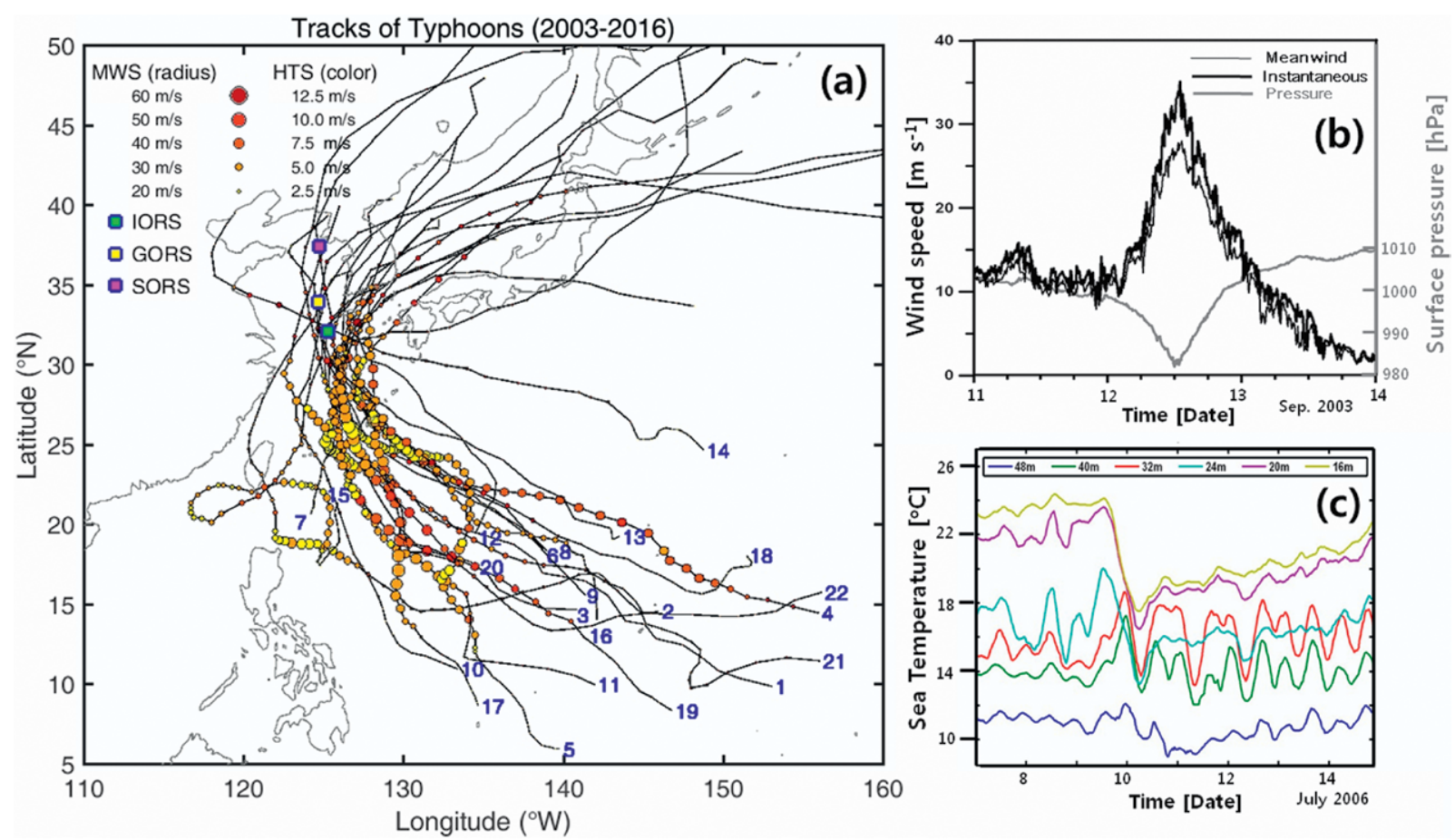

Fig. 6. (a) Typhoon tracks passing near the ocean research stations during 2003 to 2016: I) Maemi (0314), 2) Mindullle (0427), 3) Megi (04I5), 4) Songda (04I8), 5) Ewiniar (0603), 6) Nari (07II), 7) Dianmu (1014), 8) Kompasu (1007), 9) Malou (1009), 10) Meari (II05), II) Muifa (II09), I2) Kulap (III4), 13) Khanum (I207), 14) Damrey (1210), 15) Tembin (1214), 16) Bolvan (1215), 17) Sanba (1216), 18) Danas (1324), 19) Neoguri (14l8), 20) Nakri (14I2), 2I) Chanhom (1509), and 22) Chaba (1618); (b) time series of wave height and surface pressure observed during the passage of Typhoon Maemi; and (c) 7-h moving averaged ocean temperature at various water depths during Typhoon Ewiniar. In (a), the size and color of filled circles depend on the maximum wind speed (MWS) and the translation speed (HTS), respectively. 
decreased by up to $12^{\circ} \mathrm{C}$ because of the mixing of two water masses-the surface water and the YSBCW-between which the temperature varied $15^{\circ} \mathrm{C}$ within the first $50 \mathrm{~m}$ near the I-ORS during the summer (Moon et al. 2010; Moon and Kwon 2012). The significant cooling led to a rapid decrease in intensity of the typhoon.

Recently, it has been reported that ocean waves can influence the intensity of the typhoon through the air-sea heat/momentum exchange processes (Babanin 2006; Moon et al. 2004). I-ORS is located in the path of typhoons, which allows it to measure and investigate roles of ocean waves in air-sea fluxes in high wind conditions. Along with these ocean station data, wave buoys deployed around the Korean Peninsula (see Fig. 7) can also be additional sources to study the physics of air-sea interactions and wind-wave dynamics. Therefore, I-ORS is expected to provide basic data for typhoon prediction as well as understanding of the characteristics of typhoon-induced ocean waves. The data from the I-ORS can also be used for the development and verification of oceanic, atmospheric, and wave models.

\section{ATMOSPHERIC CHEMISTRY} OBSERVATIONS. At the I-ORS, the ozone $\left(\mathrm{O}_{3}\right)$ measurements began in June 2003 and continued through 2010; data obtained during this period highlighted the influence of the Chinese outflows on the regional air quality of northeast Asia (Han et al. 2015). The measurements at the I-ORS resumed in 2014, although now measurements of $\mathrm{PM}_{2.5}$ mass were also taken. More instruments were installed during this period at the S-ORS, including those for $\mathrm{CO}, \mathrm{CO}_{2}, \mathrm{CH}_{4}$, and black carbon. The S-ORS is much closer to land than the other stations and, depending on the meteorological conditions, is able to detect continental plumes (e.g., Kang et al. 2017). We note that the concentration of $\mathrm{O}_{3}$ was found to be higher at the I-ORS than it was at the S-ORS. However, the atmospheric concentration of $\mathrm{PM}_{2.5}$ was higher at the S-ORS than it was at the I-ORS, particularly during the colder months (Fig. 8).

As shown in Fig. 8, the scatterplots of the $\mathrm{O}_{3}$ versus the $\mathrm{PM}_{2.5}$ concentrations at the two sites are quite similar to one another. Contamination was removed by 2 filters at 10 neighboring values (Cvitaš et al. 2004). There were found to be two distinct regimes for the formation and accumulation of $\mathrm{PM}_{2.5}$ and $\mathrm{O}_{3}$ in the atmosphere, albeit there were limitations associated with temporal coverage of the data. At both sites, the $\mathrm{PM}_{2.5}$ and $\mathrm{O}_{3}$ concentrations were at most $50 \mathrm{~g} \mathrm{~m}^{-3}$ and $60 \mathrm{ppbv}$, respectively, implying these measurements represent the regional background concentrations of these particles in the atmosphere over northeast Asia (Parrish et al. 2012). In the study region, the meteorological conditions are a primary factor determining the sources of the major precursors of $\mathrm{PM}_{2.5}$ and $\mathrm{O}_{3}$ and their transport pathways, meaning these conditions play a significant role in determining the nature and degree of atmospheric processing of these particles (Lim et al. 2018). For these reasons, elevated concentrations of $\mathrm{PM}_{2.5}$ and $\mathrm{O}_{3}$ were found to be episodic with respect to the seasons (Lee et al. 2015). At the S-ORS, high concentrations of $\mathrm{PM}_{2.5}$ and $\mathrm{O}_{3}$ were observed during the spring and summer, respectively. In contrast, at the I-ORS, high concentrations of $\mathrm{PM}_{2.5}$ and $\mathrm{O}_{3}$ were observed during the winter and spring, respectively.

During the Asian summer monsoon, the concentrations of atmospheric constituents tend to decrease. This is due to decreased emissions from combustion processes coupled with weak continental outflows. As a result, the $\mathrm{O}_{3}$ and $\mathrm{PM}_{2.5}$ concentrations were lowest during these periods. The difference between the concentrations of these particles at the two sites was much less significant during the warmer months. However, the Chinese outflow is efficiently transported over the Yellow Sea, elevating the concentration of $\mathrm{PM}_{2.5}$ during the cold months in this area. The episodic increase in $\mathrm{PM}_{2.5}$ was evident at the S-ORS, and the hourly mean concentration often exceeded the national standard of air quality, which is $100 \mathrm{~g} \mathrm{~m}^{-3}$. These 
results demonstrate that these two ocean research stations in the Yellow Sea are ideal for observing the impact of continental outflows on regional air quality and measuring baseline concentrations of these atmospheric particles over northeast Asia.

\section{OCEANOGRAPHIC OBSERVATIONS AND APPLICATIONS FOR PROCESS STUDIES.} Calibration and validation of SST and ocean surface wave measurements. The I-ORS, which provides the longest time series data among the three KORS, is located on a broad and shallow shelf in the northern part of the East China Sea, where autonomous data from typical profiling floats (e.g., Argo floats) are not available. Hence, continuous and real-time
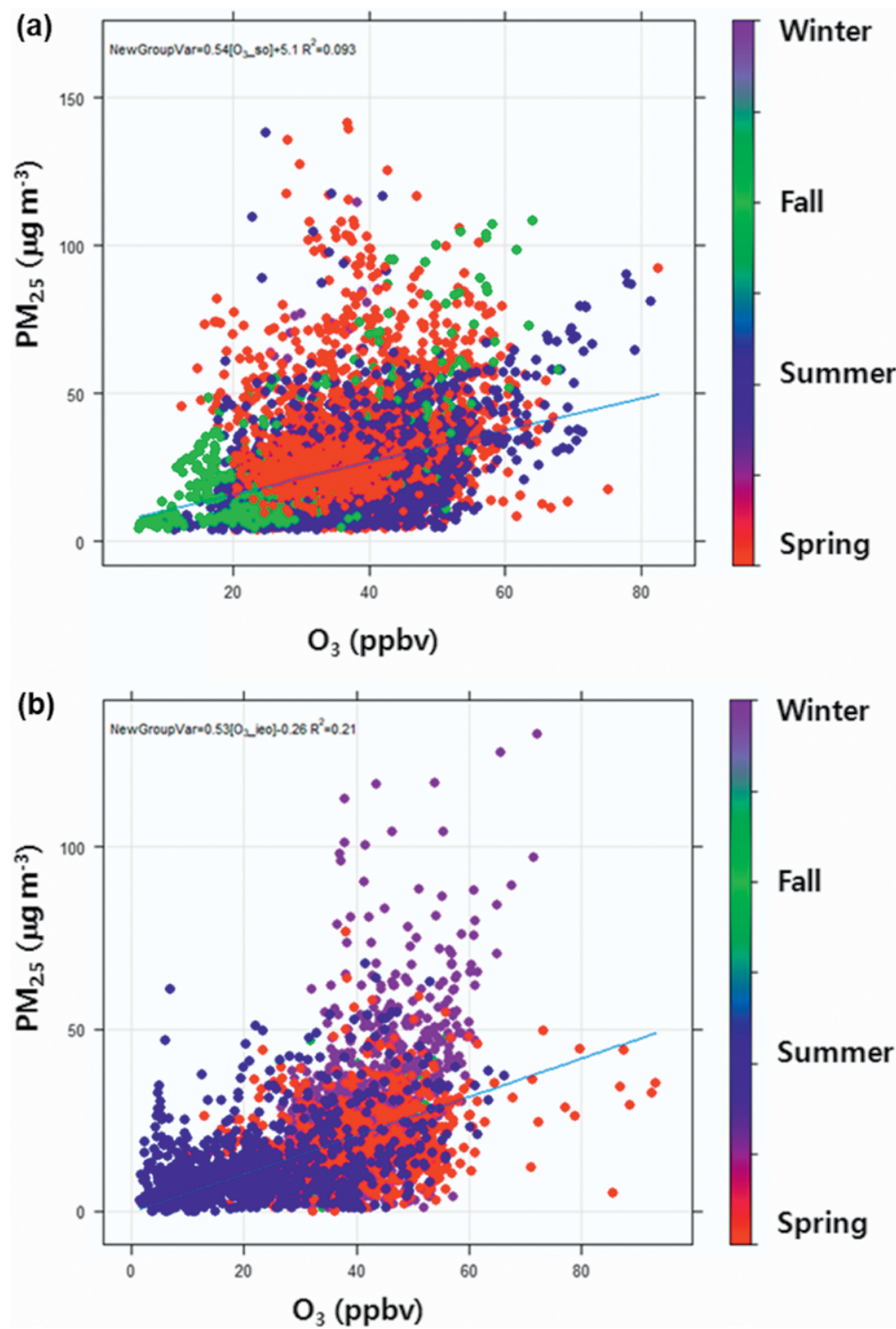

FIG. 8. Relationship between $O_{3}$ and $P M_{2.5}$ at the (a) S-ORS and (b) I-ORS during the period when the data are available at the two sites. monitoring of spatiotemporal changes in key oceanographic parameters like SST at the I-ORS is increasingly important for improving the understanding and prediction of climate change, marine ecosystems, and air-sea interactions. For this reason, a new algorithm for continuously providing SST data using a thermal infrared (TIR) sensor mounted at the I-ORS has been developed (Kang et al. 2017) (Table 2). The TIR-based SST data collected at the I-ORS in a continuous and real-time manner have been validated by comparing them with separate in situ SST measurements taken during 17 to 26 May and 15 to 18 July 2015 , yielding an accuracy of $0.72-0.85 R^{2}$ and $0.37^{\circ}-0.90^{\circ} \mathrm{C}$ rootmean-square error (RMSE). The SST can be estimated using in situ subsurface (5-, 20-, and 40-m depth) temperature measurements, yet the difference between the TIR-based SST data and SST estimated using the in situ subsurface temperatures was often significant, particularly when the bulk mixed layer temperature is not close to SST (e.g., during August, November, and December 2016) (Fig. 9 on top). With no TIRbased SST measurements, the SST may unrealistically over- or underestimated as discussed in Kang et al. (2017). Along with SST data obtained at future research stations in this and other seas, the TIR-based SST data obtained at the I-ORS will be used for calibrating remote SST data obtained from existing and future satellites.

The radar-type observation, Miros Wave Radar (MWR), equipment for ocean surface wave measurements are equipped at the KORS. MWR emits microwave and analyzes backscattering signals to observe two-dimensional propagation of ocean surface waves. It is essential to perform quality verification for scientific analysis because the MWR has low reliability at low-wind and calm-wave conditions. The MWR analysis software had been used by applying optimum filter configuration (Min et al. 2018) to secure reliability of the observed wave data by comparing to wave observations from the Directional Waverider buoy, which has been widely used by commercial companies and local 
authorities for many years, thus being regarded as an industry standard (Uncles and Mitchell 2017). Range Finder is also being operated to observe ocean waves as an auxiliary instrument for measuring the sea surface height, and thus can also monitor sea level variations due to the surface waves, contributing to the quality assurance of ocean surface wave measurements.

Underwater sound channel and nonlinear internal waves in and around the I-ORS. In the northern East China Sea, $\sim 50 \mathrm{~km}$ east of the I-ORS, an intensive field experiment named the Shallow-Water Acoustic Variability Experiment 2015 (SAVEX-15) was conducted at a water depth of $100 \mathrm{~m}$ during 14-28 May 2015. The aim of the experiment was to obtain oceanographic and underwater acoustic data simultaneously (Fig. 10a, left). Moored thermistors (50 sensors), acoustic Doppler current profilers (ADCPs; $150 \mathrm{kHz}$ ), standard stationary CTDs (26 casts), and underwater CTDs (1,062 casts) were used to measure spatiotemporal variations in the flow and the physical water properties during the experiment. An underwater sound channel (USC) usually observed in deep water [e.g., a deep sound channel or sound fixing and ranging (SOFAR) channel] was discovered in this shallow water in the vicinity of the I-ORS during the experiment (Song et al. 2018). The formation of this
TABLE 2. Specifications of the thermal infrared (TIR) sensor attached to the I-ORS (Kang et al. 20I7).

\begin{tabular}{|l|l|}
\hline TIR sensor & FLIR A310 \\
\hline Field of view & $45^{\circ} \times 34^{\circ}$ \\
\hline Spatial resolution & $1.36 \mathrm{mrad}$ \\
\hline Spectral range & $7.5-13 \mu \mathrm{m}$ \\
\hline Focal length & $18 \mathrm{~mm}$ \\
\hline Thermal sensitivity & $0.05^{\circ} \mathrm{C}$ at $+30^{\circ} \mathrm{C}$ \\
\hline IR resolution & $320 \times 240$ pixels \\
\hline
\end{tabular}

"thermal" USC is due to a temperature inversion; that is, the water temperature decreases with depth to approximately $40 \mathrm{~m}$ (minimum sound speed layer) and then begins to increase (Fig. 10b). Experimental data showed an abundance of isothermal or isopycnal undulations at diurnal, semidiurnal, and higher frequencies; these undulations are associated with oceanic internal (inertial gravity and pure gravity) waves. In particular, nonlinear internal waves (NLIWs) actively formed, transformed, and propagated throughout the SAVEX-15 area. Thus, solitary (rather than sinusoidal) isothermal undulations at time scales ranging from several to tens of minutes corresponding to the buoyancy or stratification frequency were observed at the moored thermistors
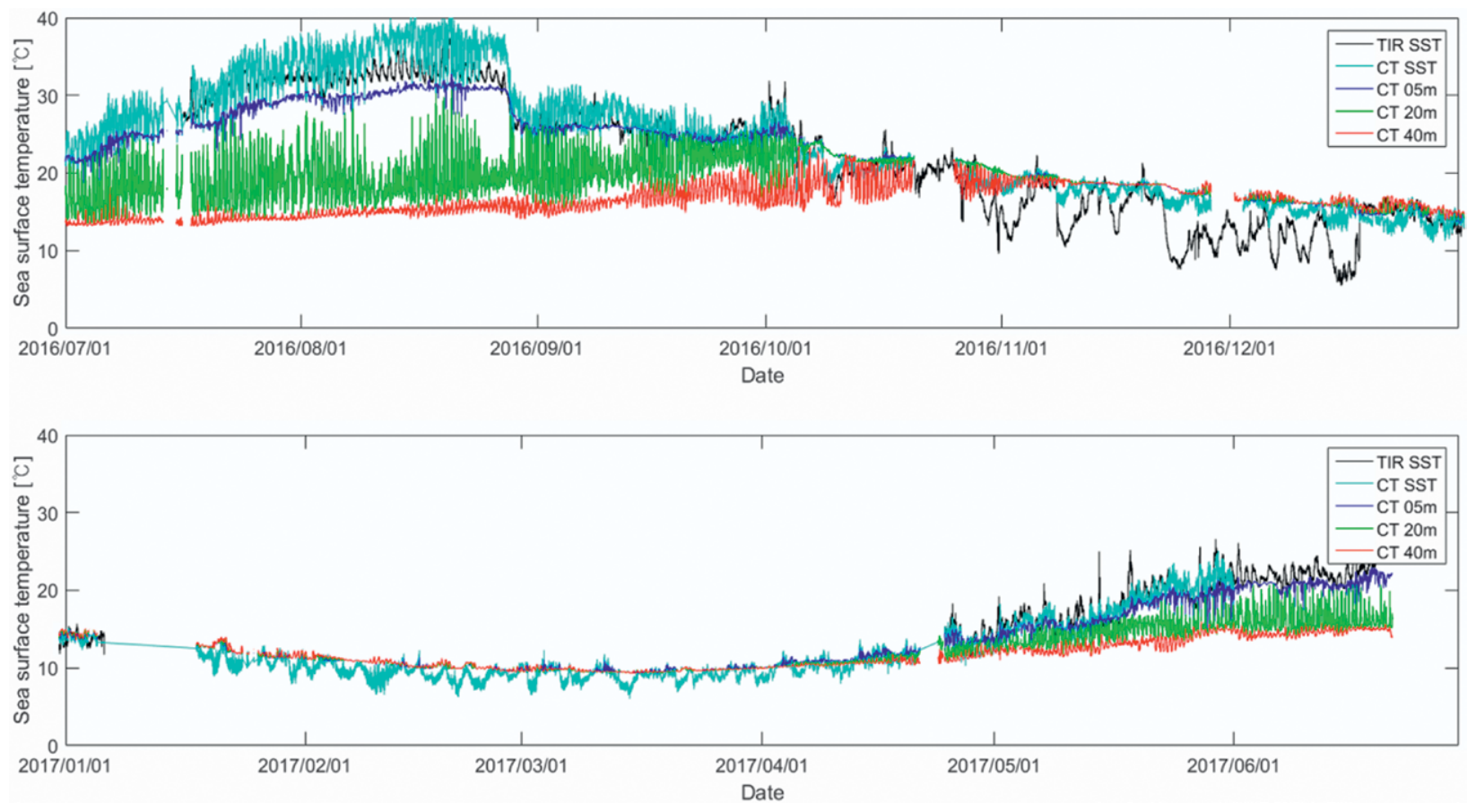

FIG. 9. Time series of SST observed using the thermal infrared sensor attached to the I-ORS (black) and estimated (sky blue) using in situ subsurface measurements (blue: $5 \mathrm{~m}$, green: $20 \mathrm{~m}$, and red: $40 \mathrm{~m}$ ). The remotely sensed and separately validated SST (black) occasionally deviates significantly from the SST estimated from subsurface measurements, highlighting the need of TIR-based SST measurements. 
and CTDs (Fig. 10b). The NLIWs' typical propagation speed of approximately $0.5 \mathrm{~m} \mathrm{~s}^{-1}$ and characteristic width of approximately $300 \mathrm{~m}$ were generally consistent with the theoretical NLIWs' amplitude $(\sim 5 \mathrm{~m})$ in the area for that season (Cho et al. 2016).

Recently, two regional-scale research cruises were conducted during February 2017 and April 2018 in the northern East China Sea covering the I-ORS location as part of the East Asian Sea Time series (EAST) program (Fig. 10a, center and right). The aim of these cruises was to observe the physicochemical properties of the seawater in the region (EAST-II region) and identify the transport of heat, salt, and materials from the East China Sea (EAST-II region) to the East Sea (EAST-I region). Environmental changes in the
East Sea are known to be affected by these transport processes through the Korea Strait because of its deep ventilation due to the hydrological cycle and atmospheric forcing in its northern region (Yoon et al. 2018). Both cruises traveled along one of the observation lines (C line) passing through I-ORS. Data collected during the cruises, along with those previously collected, have been used for comparison with data obtained near the I-ORS. Additionally, the time series data collected at the I-ORS have also been used to interpret the results within the context of "snapshot" environments sampled during the cruises.

Both small- and regional-scale oceanographic cruises will be conducted in the vicinity of the I-ORS in the coming years, which will provide data for stud- (a)

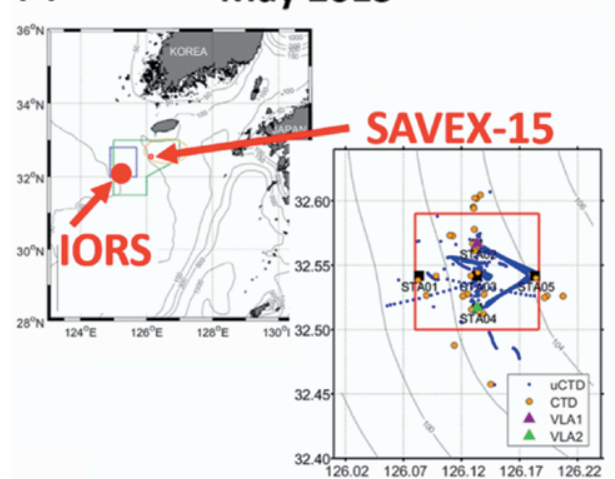

Feb. 2017

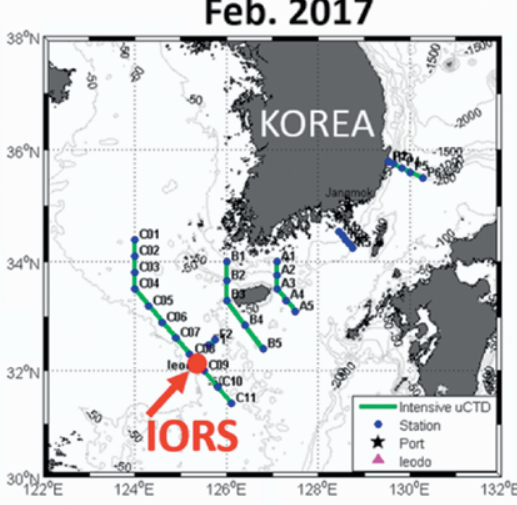

Apr. 2018

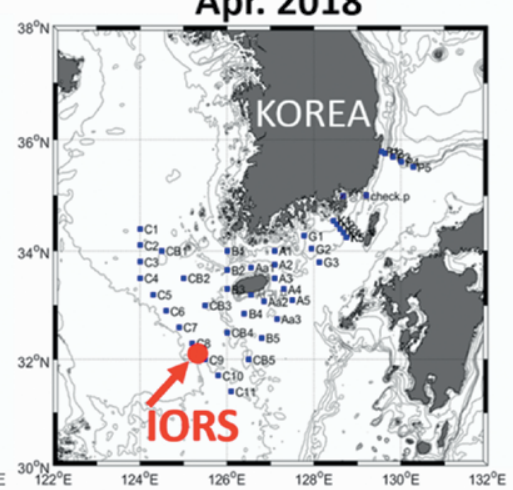

(b)
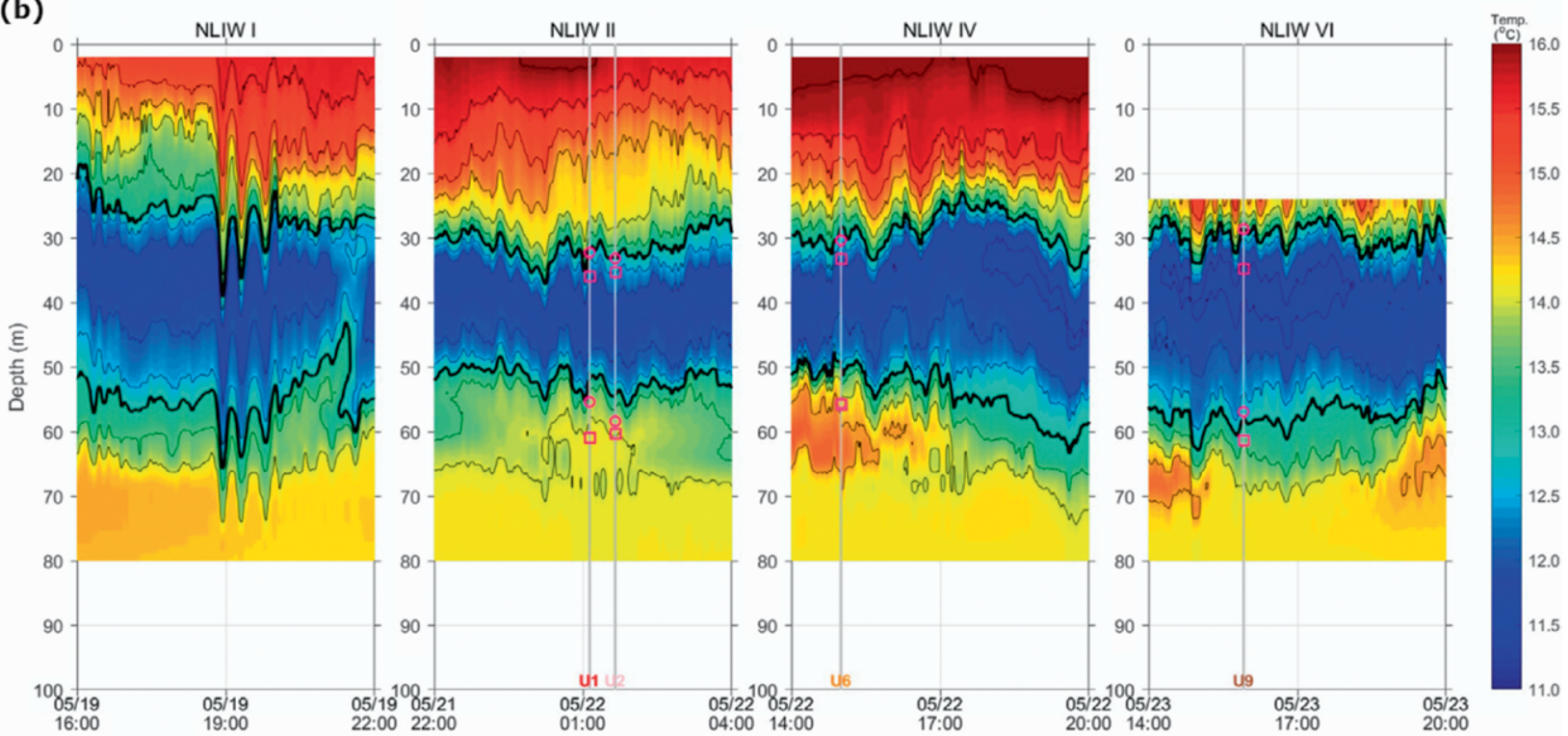

FIG. 10. (a) Areas and locations of field sampling around the I-ORS using oceanographic research vessels during (left) May 2015 via SAVEX-15 and (middle) February 2017 and (right) April 2018 via the EAST programs. The locations of the I-ORS and SAVEX-15 area are represented by the red circles and box, respectively. (b) Timedepth contour plots of water temperature observed at one of the moorings in the SAVEX-15 area (water depth: $100 \mathrm{~m}$ ), $\sim 50 \mathrm{~km}$ east of the I-ORS during May 2015. The contour interval is $0.5^{\circ} \mathrm{C}$ and the color scale is shown to the right. The thick contour lines correspond to the $13.0^{\circ} \mathrm{C}$ isotherm and are consistent with those observed using independent ship-based sampling (CTD) near the mooring (red circles and boxes). 
ies of USC and NLIWs and will provide additional data for comparison with that already collected at the I-ORS. Satellite synthetic aperture radar images taken in the vicinity of the I-ORS show spiral, wedge, and arclike NLIWs due to the local formation, reinitiation, and multidirectional radiation from the shallow sill near the I-ORS (Nam et al. 2018). Further intensive experiments in the vicinity of the I-ORS will enable us to obtain a deeper understanding of the formation, transformation, evolution, and dissipation of the NLIWs in the area. Moreover, we need to better understand phenomena whose time scales are longer than those possessed by NLIWs by analyzing in situ observational data collected in and around the I-ORS. For example, we would like to study the diurnal cycles of the SST and surface current in the area. Because the latitude of the I-ORS is near the critical latitude where the local inertial period is identical to the diurnal period, a resonant response to sea-/land-breeze forcing, subsequent eddy heat flux, and resulting mean flow are expected to be similar to the nature of these phenomena in other regions (i.e., off the Southern California coast) (Nam and Send 2013), which is left as one of our future study topics.

\section{DATA AVAILABILITY AND POLICY.} Summarized data availability. Below is a summary of the research data available for use in collaboration with other scientists:

- The platforms in use consist of three ocean research stations (I-ORS, G-ORS, and S-ORS) currently in operation and possess instruments used in variety of disciplines, including CTDs and those designed to study environmental variability at multiple scales in space and time.

- The variables considered in this study are both atmospheric and oceanographic.

- The atmospheric variables consist of wind, air temperature, pressure, humidity, precipitation, solar radiation, UV radiation, and amount of daylight. The typical sampling interval of these variables is $1 \mathrm{~min}$. The other atmospheric particles studied are $\mathrm{PM}_{2.5}$ (black carbon), $\mathrm{CO}, \mathrm{CO}_{2}, \mathrm{O}_{3}, \mathrm{H}_{2} \mathrm{O}$, and $\mathrm{CH}_{4}$. The sampling interval is basically $1 \mathrm{~h}$.

- The oceanographic variables consist of ocean surface wave parameters (wave height, wave period, and wave direction), seawater temperature and salinity (5-, 20-, and 40-m depth over the entire period and $3,5,10,15,20,30,40$, and $50 \mathrm{~m}$ during the summer only period), current, sea level, underwater sound, and biogeochemical variables including nutrients, chlorophyll a, etc. The typical sampling interval varies from 1 to $10 \mathrm{~min}$, while nutrients and chlorophyll a are more intermittently sampled.

- Start dates of the time series measurements for I-ORS, G-ORS, and S-ORS are June 2003, October 2009, and October 2014, respectively. The three KORS is supposed to be serviced typically four times a year mainly during the warm season. Most sensors equipped at the stations are periodically calibrated and most data from the sensors (except high-frequency raw time series data need to be parameterized) are transmitted in real time via satellite communication. Efforts to produce science quality data via quality control and quality assurance are still ongoing, yet the data of present form are released to research community.

Data distribution using OceanSITES. The time series data collected at KORS are processed, calibrated, corrected, and intercompared with other measurements to rapidly provide high-quality final products. Data from in situ measurements are provided to research community in a delayed mode after calibration/validation currently via the KORS project website (http://kors .kiost.ac.kr/en/), which will be provided to the wider community for operational use, for example, WMO global GTS system, and ultimately through a global time series observation network OceanSITES (www oceansites.org) (e.g., Cronin et al. 2010; Send et al. 2010). The data in a real-time mode or near-term time series measurements are currently available from the KOOFS website (www.khoa.go.kr/koofs leng/observation/obs_real.do). The OceanSITES demonstrated the geographical importance of the KORS by developing a status map (before October 2018) that shows no site near the three KORS in the Yellow and East China Seas and potential representation of western Pacific marginal seas along with other sites within the region.

ACKNOWLEDGMENTS. We thank those associated with the "Construction of Ocean Research Stations and their Application Studies" project, funded by the Ministry of Oceans and Fisheries, South Korea, for their support. K.-J. Ha and J. Yun were supported by Institute for Basic Science under Grant IBS-R028-D1. I.-J. Moon and S. H. Nam were supported by the National Research Foundation of Korea (NRF) funded by the Ministry of Education (2017R1A2B2005019 and NRF-2018K2A9A1A01090424). S. H. Nam was partially supported by the project titled "Deep Water Circulation and Cycling in the East Sea" via KIMST, and "I-ORS" project via KHOA, funded by the Ministry of Oceans and Fisheries, and by the Agency for Defense Development (UD170006DD), South Korea. The 
joint experiment between the United States and South Korea, SAVEX-15, was funded by U.S. Office of Naval Research (N00014-13-1-0510), KIOST (PE99331), and KRISO (PES1940).

\section{REFERENCES}

Babanin, A. V., 2006: On a wave-induced turbulence and a wave-mixed upper ocean layer. Geophys. Res. Lett., 33, L20605, https://doi.org/10.1029/2006GL027308.

Byun, D.-S., H. W. Kim, J. Y. Lee, E. I. Lee, K.-A. Park, and H.-J. Woo, 2018: Converting Ieodo Ocean Research Station wind speed observations to reference height data for real-time operational use (in Korean). Korean Soc. Oceanogr., 23, 153-178, https:// doi.org/10.7850/jkso.2018.23.4.153.

Cho, C., S. H. Nam, and H. Song, 2016: Seasonal variation of speed and width from kinematic parameters of mode-1 nonlinear internal waves in the northeastern East China Sea. J. Geophys. Res. Oceans, 121, 5942-5958, https://doi.org/10.1002/2016JC012035.

Choi, D. H., and J. H. Noh, 2006: Molecular phylogenetic analyses of three Synechococcus strains isolated from seawater near the Ieodo Ocean Research Station. Ocean Sci. J., 41, 315-318, https://doi.org/10.1007 /BF03020633.

Choi, Y., K.-S. Yun, K.-J. Ha, K.-Y. Kim, S.-J. Yoon, and J. C. L. Chan, 2013: Effects of asymmetric SST distribution on straight-moving Typhoon Ewiniar (2006) and recurving Typhoon Maemi (2003). Mon. Wea. Rev., 141, 3950-3967, https://doi.org/10.1175 /MWR-D-12-00207.1.

Cronin, M. F., and Coauthors, 2010: Monitoring oceanatmosphere interactions in western boundary current extensions. Proc. OceanObs'09: Sustained Ocean Observations and Information for Society, Venice, Italy, ESA, https://doi.org/10.5270/OceanObs09 .cwp. 20 .

Cvitaš, T., and Coauthors, 2004: Spectral analysis of boundary layer ozone data from the EUROTRAC TOR network. J. Geophys. Res., 109, D02302, https:// doi.org/10.1029/2003JD003727.

Ha, K.-J., and L. Mahrt, 2001: Simple inclusion of $z$-less turbulence within and above the modeled nocturnal boundary layer. Mon. Wea. Rev., 129, 2136-2143, https://doi.org/10.1175/1520-0493(2001)129<2136: SIOZLT $>2.0 . \mathrm{CO} ; 2$.

—, Y.-K. Hyun, H.-M. Oh, K.-E. Kim, and L. Mahrt, 2007: Evaluation of boundary layer similarity theory for stable conditions in CASES-99. Mon. Wea. Rev., 135, 3474-3483, https://doi.org/10.1175/MWR3488.1.

Han, J., B. Shin, M. Lee, G. Hwang, J. Kim, J. Shim, G. Lee, and C. Shim, 2015: Variations of surface ozone at Ieodo Sea Research Station in the East China Sea and influence of Asian outflows. Atmos. Chem. Phys., 15, 122611-122621, https://doi.org/10.5194 /acp-15-12611-2015.

Heo, K.-Y., and K.-J. Ha, 2010: A coupled model study of formation and dissipation of sea fog. Mon. Wea. Rev., 138, 1186-1205, https://doi .org/10.1175/2009MWR3100.1.

— , J.-H. Kim, J.-S. Sim, K.-J. Ha, A.-S. Suh, H.-M. Oh, and S.-Y. Min, 2008: A remote sensed data combined method for sea fog detection. Korean J. Remote Sens., 24, 1-16.

_, K.-J. Ha, L. Mahrt, and J.-S. Shim, 2010: Comparison of advection and steam fogs: From direct observation over the sea. Atmos. Res., 98, 426-437, https://doi.org/10.1016/j.atmosres.2010.08.004.

$\longrightarrow$ - _ North Pacific Ocean and energetics of transient eddy activity. Mon. Wea. Rev., 140, 2860-2873, https://doi .org/10.1175/MWR-D-11-00256.1.

— , S. Park, K.-J. Ha, and J.-S. Shim, 2014: Algorithm for sea fog monitoring with the use of information technologies. Meteor. Appl., 21, 350-359, https://doi .org/10.1002/met.1344.

Kang, K. M., and Coauthors, 2017: Establishment of thermal infrared observation system on Ieodo Sea Research Station for time-series sea surface temperature extraction (in Korean). Sea, 22, 57-68, https:// doi.org/10.7850/JKSO.2017.22.3.057.

Kim, B.-C., and B. K. Choi, 2006: Variation of underwater ambient noise observed at IORS station as a pilot study. Ocean Sci. J., 41, 175-179, https://doi .org/10.1007/BF03022422.

Kim, W., J.-H. Yi, I. K. Min, and J.-S. Shim, 2018: Monitoring of structural dynamic characteristics of Socheongcho Ocean Research Station. J. Coastal Res., 85, 1191-1195, https://doi.org/10.2112/SI85-239.1.

Kim, Y. S., C. J. Jang, and S.-W. Yeh, 2018: Recent surface cooling in the Yellow and East China Seas and the associated North Pacific climate regime shift. Cont. Shelf Res., 156, 43-54, https://doi.org/10.1016/j .csr.2018.01.009.

Lee, J. H., I. Lozovatsky, S.-T. Jang, C. J. Jang, C. S. Hong, and H. J. S. Fernando, 2006: Episodes of nonlinear internal wave in the northern East China Sea. Geophys. Res. Lett., 33, L18601, https://doi .org/10.1029/2006GL027136.

Lee, S. H., C. H. Han, D. C. Shin, S. D. Hur, S. J. Jun, Y.-T. Kim, D.-S. Byun, and S. M. Hong, 2017: Characteristics of elemental and $\mathrm{Pb}$ isotopic compositions in aerosols $\left(\mathrm{PM}_{10-2.5}\right)$ at the Ieodo Ocean Research Station in the East China Sea. Environ. Pollut., 231, 154164, https://doi.org/10.1016/j.envpol.2017.08.007. 
Lee, T., and Coauthors, 2015: Characterization of aerosol composition, concentrations, and sources at Baengnyeong Island, Korea using an aerosol mass spectrometer. Atmos. Environ., 120, 297-306, https:// doi.org/10.1016/j.atmosenv.2015.08.038.

Lie, H.-J., and C.-H. Cho, 2016: Seasonal circulation pattern of the Yellow and East China Seas derived from satellite-tracked drifter trajectories and hydrographic observations. Prog. Oceanogr., 146, 121-141, https://doi.org/10.1016/j.pocean.2016.06.004.

,-- , J.-H. Lee, and S. Lee, 2003: Structure and eastward extension of the Changjiang River plume in the East China Sea. J. Geophys. Res., 108, 3077, https://doi.org/10.1029/2001JC001194.

Lim, S., M. Lee, S.-W. Kim, and P. Laj, 2018: Sulfate alters aerosol absorption properties in East Asian outflow. Sci. Rep., 8, 5172, https://doi.org/10.1038 /s41598-018-23021-1.

Min, Y. C., J.-Y. Jeong, I.-K. Min, Y. S. Kim, J.-S. Shim, and K. D. Do, 2018: Enhancement of wave radar observation data quality at the Socheongcho Ocean Research Station. J. Coastal Res., 85, 571-575, https:// doi.org/10.2112/SI85-115.1.

Moon, I.-J., and S. J. Kwon, 2012: Impact of upper-ocean thermal structure on the intensity of Korean peninsular landfall typhoons. Prog. Oceanogr., 105, 61-66, https://doi.org/10.1016/j.pocean.2012.04.008.

— , T. Hara, I. Ginis, S. E. Belcher, and H. L. Tolman, 2004: Effect of surface waves on air-sea momentum exchange: Part I. Effect of mature and growing seas. J. Atmos. Sci., 61, 2321-2333, https://doi .org/10.1175/1520-0469(2004)061<2321:EOSWOA $>2.0 . \mathrm{CO} ; 2$.

—, J.-S. Shim, D. Y. Lee, J. H. Lee, I.-K. Min, and K. C. Lim, 2010: Typhoon researches using the Ieodo Ocean Research Station: Part I. Importance and present status of typhoon observation (in Korean). Atmosphere, 20, 247-260.

—, M. Kim, M. Joh, J. Ahn, J.-S. Shim, and J. Jung, 2016: Recent record-breaking high ocean waves induced by typhoons in the seas adjacent to Korea. J. Coastal Res., 75, 1397-1401, https://doi.org/10.2112 /SI75-280.1.

Nam, S. H., and U. Send, 2013: Resonant diurnal oscillations and mean alongshore flows driven by sea/land breeze forcing in the coastal Southern California Bight. J. Phys. Oceanogr., 43, 616-630, https://doi .org/10.1175/JPO-D-11-0148.1.

_- Y.-B. Kim, J. J. Park, and K.-I. Chang, 2014: Status and prospect of unmanned, global sea observation network (In Korean). Korean Soc. Oceanogr., 19, 202-214.
—, D.-J. Kim, S.-W. Lee, B. G. Kim, K.-M. Kang, and Y.-K. Cho, 2018: Nonlinear internal wave spirals in the northern East China Sea. Sci. Rep., 8, 3473, https://doi.org/10.1038/s41598-018-21461-3.

Oh, H.-M., K.-J. Ha, K.-Y. Heo, K.-E. Kim, S.-J. Park, J.-S. Shim, and L. Mahrt, 2010: On drag coefficient parameterization with post processed direct fluxes measurements over the ocean. Asia-Pac. J. Atmos. Sci., 46, 513-523, https://doi.org/10.1007/s13143 $-010-0030-3$.

— , K.-E. Kim, K.-J. Ha, L. Mahrt, and J.-S. Shim, 2011: Quality control and tilt correction effects on the turbulent fluxes observed at an ocean platform. J. Appl. Meteor. Climatol., 50, 700-712, https://doi .org/10.1175/2010JAMC2367.1.

Park, T., C. J. Jang, J. H. Jungclaus, H. Haak, W. Park, and I. S. Oh, 2011: Effects of the Changjiang River discharge on sea surface warming in the Yellow and East China Seas in summer. Cont. Shelf Res., 31, 15-22, https://doi.org/10.1016/j.csr.2010.10.012.

Parrish, D. D., and Coauthors, 2012: Long-term changes in lower tropospheric baseline ozone concentrations at northern mid-latitudes. Atmos. Chem. Phys., 12, 11 485-11 504, https://doi.org/10.5194/acp-12 $-11485-2012$.

Send, U., and Coauthors, 2010: OceanSITES. Proc. OceanObs'09: Sustained Ocean Observations and Information for Society, Venice, Italy, ESA, https:// doi.org/10.5270/OceanObs09.cwp.79.

Song, H. C., C. Cho, W. S. Hodgkiss, S. H. Nam, S.-M. Kim, and B.-N. Kim, 2018: Underwater sound channel in the northeastern East China Sea. Ocean Eng., 147, 370-374, https://doi.org/10.1016/j .oceaneng.2017.10.045.

Uncles, R. J., and S. B. Mitchell, 2017: The use of autonomous sampling platforms with particular reference to moored data buoys. Estuarine and Coastal Hydrography and Sediment Transport, Cambridge University Press, 302-305.

Yi, J.-H., J.-S. Park, S.-H. Han, and K.-S. Lee, 2013: Modal identification of a jacket-type offshore structure using dynamic tilt responses and investigation of tidal effects on modal properties. Eng. Struct., 49, 767-781, https://doi.org/10.1016/j.engstruct.2012.12.015.

Yoon, S.-T., and Coauthors, 2018: Re-initiation of the bottom water formation in the East Sea (Japan Sea) in a warming world. Sci. Rep., 8, 1576, https://doi .org/10.1038/s41598-018-19952-4.

Yun, J., K.-J. Ha, and Y.-E. Jo, 2018: Interdecadal changes in winter surface air temperature over East Asia and their possible causes. Climate Dyn., 51, 1375-1390, https://doi.org/10.1007/s00382-017-3960-y. 

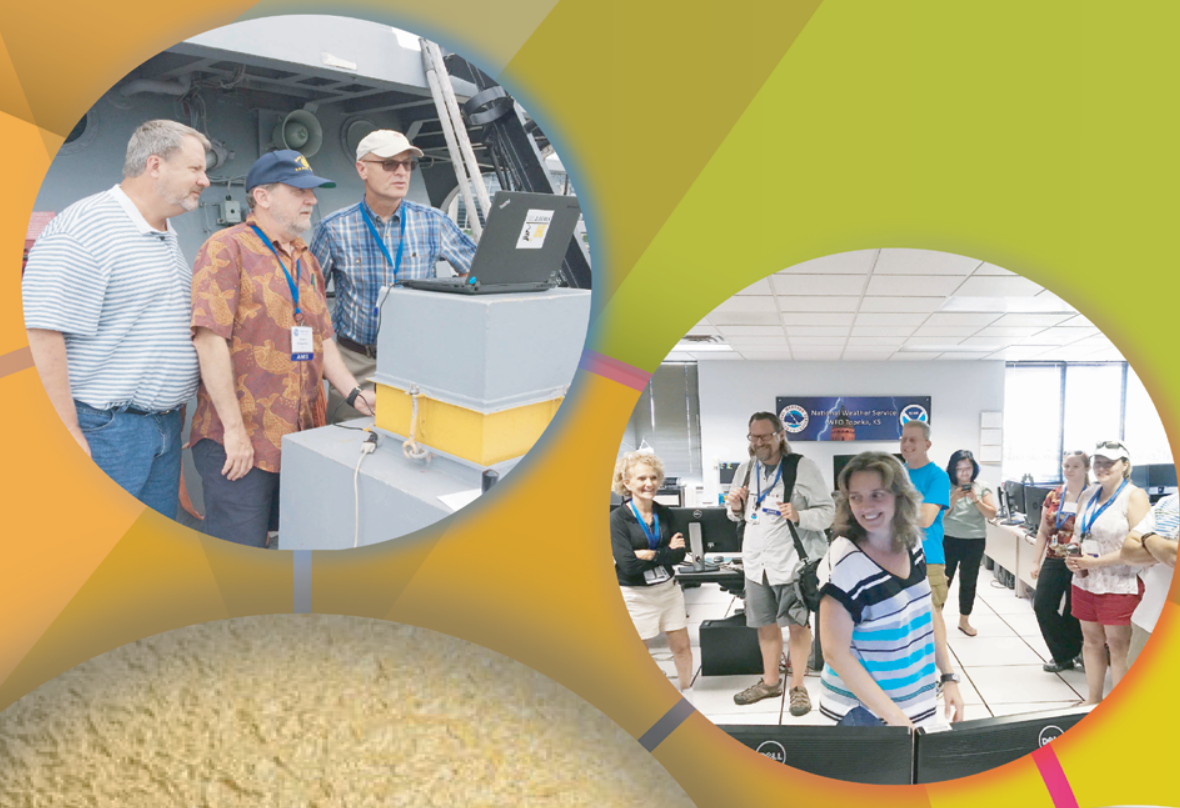

\section{ams EDUICATION}

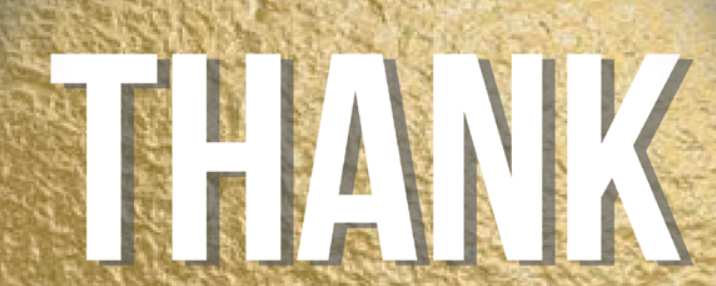

stit 